\title{
STUDIES OF RESISTANCES OF NATURAL LIQUID FLOW IN HELICAL AND CURVED PIPES
}

\author{
Michał Stosiak ${ }^{1}$ \\ Maciej Zawiślak ${ }^{1}$ \\ Bohdan Nishta ${ }^{2}$ \\ ${ }^{1}$ Wrocław University of Science and Technology \\ ${ }^{2}$ Sumy State University, Ukraine
}

\begin{abstract}
The main aim of this research was to determine in three ways, i.e. experimentally, analytically and by means of numerical modelling, the resistances of the flow of a natural liquid in a helical pipe and in curved pipes. The analyses were carried out for three pipes: one helical pipe and two curved pipes. Each of the pipes was $2 \mathrm{~m}$ long and its inside diameter was $4 \mathrm{~mm}$. The experiment was carried out on a test stand making it possible to measure the rate of the flow of the liquid, the temperature at the pipe's inlet and outlet and the pressure at the pipe's inlet and outlet. The resistances of the flow of the liquid were calculated from analytical or empirical formulas found in the literature on the subject. Moreover, numerical modelling was performed using the finite volume element method.
\end{abstract}

Keywords: flow, resistance of flow, helical pipe, curved pipe, natural liquid, laminar flow

\section{INTRODUCTION}

There is practically no industry which to a greater or lesser extent does not need to move liquids or gases through pipes, ducts and other installations. The hydraulic or gas networks can vary widely in their complexity.

In some cases, these are backbone networks consisting of mainly very long straight conduits (oil and gas pipelines, water and steam pipes and ducts in air ventilation systems in large businesses).

In other cases, these are relatively short networks with a large number of differently shaped and branched parts and various obstructions in the form of throttling or control components. Hydraulic pumps, as well as motors, consist of consecutive, local obstacles of complex shapes in close proximity to each other [1]. In such elements besides volumetric losses [2], there are losses due to the flow of a medium through internal channels.
Hydraulic drive is also widely used in ships and other vessels. In marine applications is especially important for the whole system to be watertight due to the corrosive properties of seawater that can easily damage the elements. Furthermore, it is crucial from the standpoint of reliability and efficiency, to have reliable tools that can estimate the amount of flow losses in the system. During the design phase, it is convenient to use CFD modelling, however, acquired results should be validated experimentally.

In all the cases, the hydraulic (aerodynamic) resistances of the flow of a liquid or a gas need to be calculated. Furthermore, the modern design of structures with complicated forms of hydraulic and gas networks requires knowledge of the basic physical and mechanical processes which take place in complex network components and should take into account the recommendations for improving the flow conditions and reducing the hydraulic resistance of such components [3]. 
Losses of pressure always occur during the transport of liquids or gases through conduits [4]. The size of the losses affects the demand for power needed to transport the liquids or the gases and thereby has a bearing on the operating costs of the entire transmission system. Understanding of flow losses is also important in pumps, motors and hydraulic valves in which, due to the complex shapes of apertures and channels [5], known and simple relationships cannot be applied with satisfactory accuracy.

Therefore calculations of flow losses in hydraulic systems are of vital importance. The number of pipe configurations is huge and so not all of them can be presented here. Therefore three different pipes: a helical pipe and two curved pipes were selected for consideration in this paper.

\section{EXPERIMENTAL DETERMINATION OF LIQUID FLOW RESISTANCES}

\section{DESCRIPTION OF STUDIED PIPES}

As part of this research the resistances of the flow of a liquid in three rigid pipes which had been formed from steel pipes manufactured by Parker Hannifin were studied. Each of the pipes is $2 \mathrm{~m}$ long and its inside diameter amounts to $4 \mathrm{~mm}$ :

№1 - a helical pipe (fig. 1.1.(a)),

№2- a curved pipe with two long straight sections and a bend having a radius of $32.5 \mathrm{~mm}$ (fig. 1.1.(b)),

№3- a curved pipe with 9 bends each having a radius of $40 \mathrm{~mm}$ (fig. 1.1.(c)).

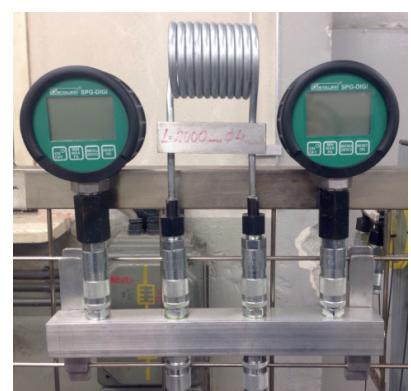

a)

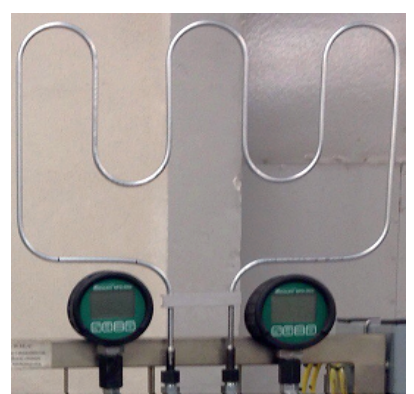

c)

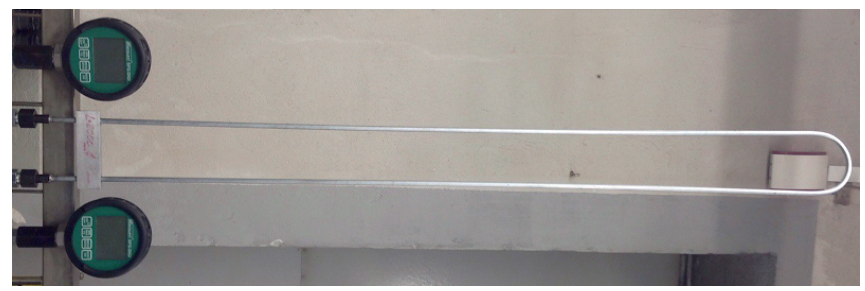

b)

Fig. 1.1. Studied pipes
Measurements of the roughness of the pipe's interior side (fig. 1.2) were carried out using a HOMMEL TESTER T1000. The results of the measurements are presented in table 1.1.

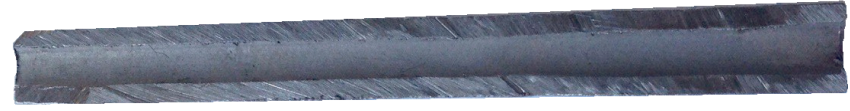

Fig. 1.2. Interior side of pipe

Table 1.1. Roughness measurements

\begin{tabular}{|c|c|c|c|c|}
\hline 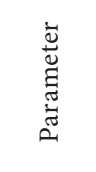 & 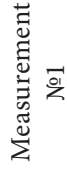 & 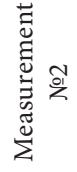 & 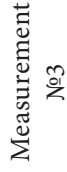 & 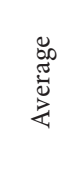 \\
\hline $\mathrm{Ra}, \mu \mathrm{m}$ & 1.29 & 1.22 & 1.26 & 1.257 \\
\hline $\mathrm{Rz}, \mu \mathrm{m}$ & 7.78 & 7.54 & 8.12 & 7.813 \\
\hline $\mathrm{Rt}, \mu \mathrm{m}$ & 9.34 & 8.36 & 9.48 & 9.06 \\
\hline
\end{tabular}

\section{PROPERTIES OF WORKING LIQUID}

Hydraulic oil FUCHS RENOLIN VG 46 was used as the working liquid. RENOLIN VG 46 is intended for hydraulic devices which can operate at high temperatures in equipment where the pumps require hydraulic oils reducing abrasion in mixed friction conditions. This oil is highly resistant to ageing and is characterized by high oxidation stability. Its foaming tendency is low and its air releasing power is high. The specifications of the oil are given in table 1.2 [6].

Table 1.2. Specifications of hydraulic oil FUCHS RENOLIN VG 46.

\begin{tabular}{|l|c|}
\hline \multicolumn{1}{|c|}{ Parameter } & Numerical value \\
\hline Density at $15^{\circ} \mathrm{C}, \mathrm{kg} / \mathrm{m}^{3}$ & 877 \\
\hline Kinematic viscosity at $40^{\circ} \mathrm{C}, \mathrm{mm}^{2} / \mathrm{s}$ & 46 \\
\hline Kinematic viscosity at $100^{\circ} \mathrm{C}, \mathrm{mm}^{2} / \mathrm{s}$ & 6.8 \\
\hline Viscosity index & 95 \\
\hline Fluidity loss temperature, ${ }^{\circ} \mathrm{C}$ & -21 \\
\hline
\end{tabular}

\section{DESCRIPTION OF LABORATORY TEST STAND}

The test stand shown in fig. 1.3 was used to measure the resistances of the flow of the hydraulic oil. The hydraulic oil is delivered to the studied pipe's inlet, where temperature T1 and pressure $\mathrm{p} 1$ are measured, by a pump via a pipe with a relief valve. Temperature was measured by a HYDROTECHNIK HySense TE100 ISDS temperature sensor. The pressure at the studied pipe's inlet was measured by a STAUFF SPD-DIGI$\mathrm{B} 0100-\mathrm{B}$ pressure gauge with a measuring range of $0-100$ bar. The pressure at the pipe's outlet was measured by a STAUFF SPD-DIGI-B0016-B pressure gauge with a measuring range of 1-16 bar. After leaving the studied pipe the oil was delivered to a HYDROTECHNIK HySense QG100 flow meter with a measuring range of $0.7-70 \mathrm{l} / \mathrm{min}$. Then the oil returned to the tank. The data from the temperature sensors and the flow 
meter were read off a HYDROTECHNIK Multi System 8050 multichannel measurement and control instrument.

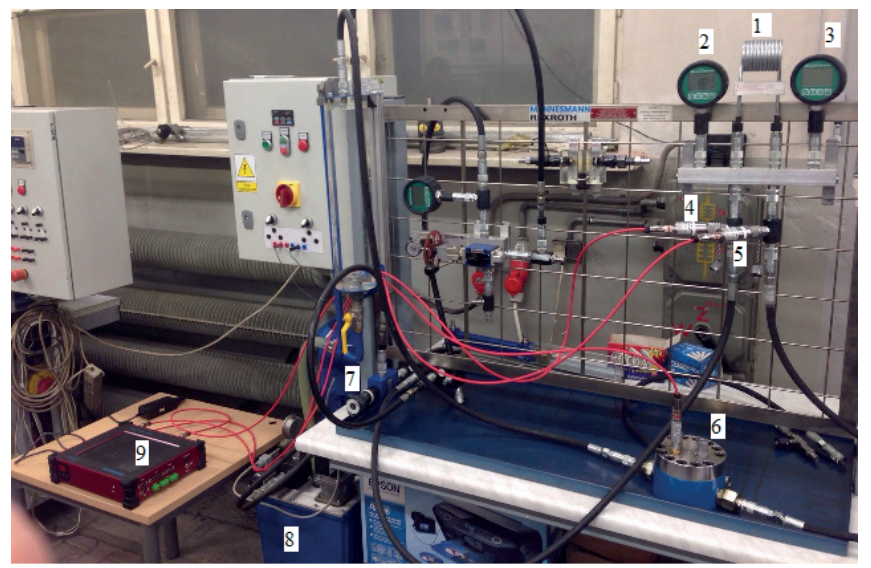

Fig. 1.3. Measuring stand: 1 - pipe in which flow resistance is investigated, 2 - igital pressure gauge at pipe's inlet, 3 - digital pressure gauge at pipe's outlet, 4 - thermometer at pipe's outlet, 5 - thermometer at pipe's outlet, 6 - flow meter, 7 - relief valve, 8 - tank, 9 - multichannel measurement and control instrument

\section{DETERMINATION OF MEASUREMENT UNCERTAINTY}

In order to determine the accuracy (by determining the maximum systematic uncertainty) of the pressure, flow rate and liquid temperature recording one should add up the individual uncertainties occurring in the whole measuring circuit. The maximum measurement uncertainty for the circuit measuring pressure $\mathrm{p}$, flow rate $\mathrm{Q}$ and temperature is expressed by the relation [7]:

$\delta_{\text {max }}=\left|\delta_{\text {sensor }}\right|+\left|\delta_{\text {amplifier }}\right|+\left|\delta_{\text {computer }}\right|$

The following were used in the experiments:

- a HYDROTECHNIK HySense TE100 ISDS temperature sensor with $\delta_{\text {Tsensor }}< \pm 1 \%$ of the end value;

- a STAUFF SPD-DIGI-B0100-B pressure gauge with $\delta_{p \text { sensor }} \leq \pm 0.5 \%$;

- a STAUFF SPD-DIGI-B0016-B pressure gauge with $\delta_{p \text { sensor }} \leq \pm 0.5 \%$;

a HYDROTECHNIK HySense QG100 flow meter with $\delta_{Q \text { sensor }} \leq \pm 0.4 \%$;

- the frequency input of the HYDROTECHNIK Multi System 8050 multichannel measurement and control instrument for flow rate recording, with $\delta_{\text {Q computer }} \leq \pm 0.02 \%$;

- the analogue inputs of the HYDROTECHNIK Multi System 8050 multichannel measurement and control instrument for temperature recording, with $\delta_{\text {T computer }} \leq \pm 0.1 \%$.

Taking into account the individual measurement uncertainties, the pressure recording uncertainty was evaluated to amount to $\delta_{p \max } \leq 0.5 \%$, the flow rate recording uncertainty to $\delta_{Q \max } \leq 0.42 \%$ and the temperature recording uncertainty to $\delta_{T \max } \leq 1.1 \%$.

\section{PROCESSING OF MEASUREMENT RESULTS}

The obtained measurement results are presented as graphs in fig. 1.4.

According to fig. 1.4, the highest pressure losses occur in the helical pipe, whereas the lowest pressure losses are in pipe №2 which has the longest straight section of all the studied pipes.

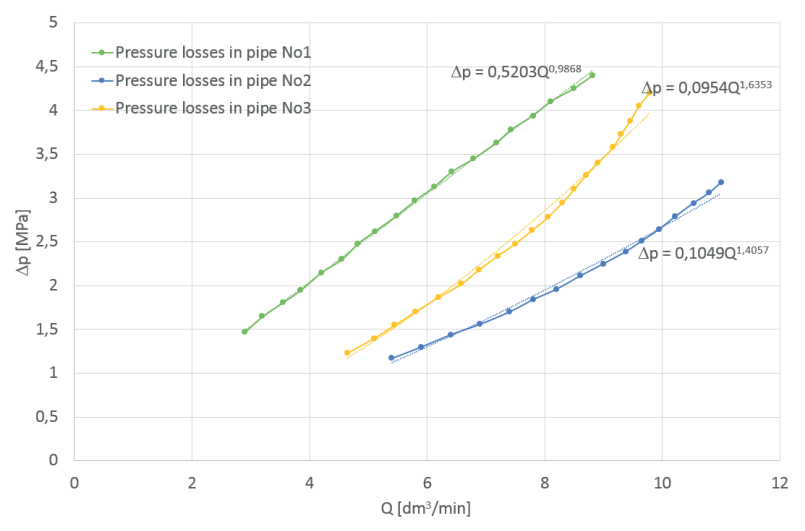

Fig. 1.4. Pressure losses versus flow rate

Values of the exponents a after data approximation with an exponential function shows, that for pipe 1 flow is laminar for the whole range of $\mathrm{Q}$, and for pipes 2 and 3 the type of the flow changes to transitional state with a dominance of turbulent flow.

\section{ANALYTICAL CALCULATION OF LIQUID FLOW RESISTANCES}

\section{INPUT DATA}

The input data for the calculations are given in table 2.1. Tab. 2.1. Input data.

\begin{tabular}{|l|c|c|c|}
\hline \multirow{2}{*}{ Parameter } & \multicolumn{3}{|c|}{ Pipe number } \\
\cline { 2 - 4 } & №1 & \multicolumn{3}{|c|}{4 №2 } & №3 \\
\hline Inside diameter, mm & $36 \cdot 10^{-6}$ \\
\hline Initial oil temperature, ${ }^{\circ} \mathrm{C}$ & 39.4 & 39.5 \\
\hline Coefficient of kinematic viscosity, $\mathrm{m}^{2} / \mathrm{s}$ & \multicolumn{3}{|c|}{877} \\
\hline Density, $\mathrm{kg} / \mathrm{m}^{3}$ & \multicolumn{3}{|c|}{} \\
\hline Flow rate, $\mathrm{m}^{3} / \mathrm{s}$ & $1.354 \cdot 10^{-4}$ & $1.835 \cdot 10^{-4}$ & $1.626 \cdot 10^{-4}$ \\
\hline
\end{tabular}

\section{CALCULATION OF REYNOLDS NUMBER FOR STUDIED PIPES}

The Reynolds number for the studied pipes can be calculated from the formula [8]:

$$
R e=\frac{c d_{h}}{v}=\frac{4 Q}{\pi d_{h} v}
$$


where: $c$ - the average flow rate, $v$ - the coefficient of the kinematic viscosity of the liquid, $d_{h}$ - the hydraulic diameter of the pipe, $Q$ - the rate of flow.

Substituting the appropriate values one gets $R e_{1}=936.78$, $R e_{2}=1270, R e_{3}=1125$. The calculations show that a laminar flow will occur in all the three pipes.

\section{CALCULATION OF LIQUID FLOW RESISTANCES FOR STUDIES PIPES}

In order to calculate pressure losses along the straight sections of the pipes for the laminar flow of the oil one can use the relation [8]:

$$
\Delta p=\frac{64}{R e} \rho \frac{l}{d} \frac{c^{2}}{2}
$$

Since the studied pipes vary in the length of their straight section the overall length of the straight section of each of the pipes is calculated below and the pressure losses for the sections are determined. The results are presented in table 2.2. Tab. 2.2. Length of straight section for each pipe and respective pressure losses.

\begin{tabular}{|l|c|c|c|}
\hline \multirow{2}{*}{ Calculated quantity } & \multicolumn{3}{|c|}{ Pipe number } \\
\cline { 2 - 4 } & №1 & №2 & №3 \\
\hline Overall length of straight section, $\mathrm{m}$ & 0.1 & 1.898 & 1.15 \\
\hline Pressure loss, $\mathrm{Pa}$ & $0.87 \cdot 10^{5}$ & $22.37 \cdot 10^{5}$ & $12.01 \cdot 10^{5}$ \\
\hline
\end{tabular}

The pressure losses in the helical part of pipe №1 were calculated on the basis of $[9,10,12]$.

Dean number $D e$ and critical Dean $D e_{k r}$ can be calculated from the formulas [9]:

$$
\begin{gathered}
D e=R e \sqrt{\frac{d}{R}} \\
D e_{k r}=2 \cdot 10^{4}\left(0.5 d / R^{*}\right)^{0,82} \\
R^{*}=R\left[1+\frac{t_{p}}{(2 \pi R)^{2}}\right]
\end{gathered}
$$

where: $t_{p}$ - the pitch of the helix, $R$ - the radius of the helix (fig. 2.1).

For the given helical part of pipe №1: $t_{p}=6 \mathrm{~mm}, R=23.5$ $\mathrm{mm}, D e=386$ and $D e_{k r}=2649$.

If the Dean number is lower than the critical one can use the following formula for the coefficient of hydraulic friction, taking into consideration the circular cross section of the pipe and the laminar flow of the liquid [9]:

$$
\begin{gathered}
\lambda=0.1008(\operatorname{Re} \sqrt{d / 2 R})^{0.5}\left[1+3.945(\operatorname{Re} \sqrt{d / 2 R})^{-0.5}+7.782(\operatorname{Re} \sqrt{d / 2 R})^{-1}+\right. \\
\left.+9.097(\operatorname{Re} \sqrt{d / 2 R})^{-1.5}+5.608(\operatorname{Re} \sqrt{d / 2 R})^{-2}\right] \frac{64}{\operatorname{Re}}
\end{gathered}
$$

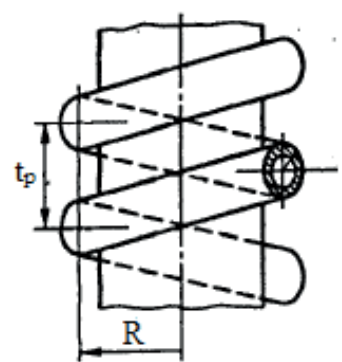

Fig. 2.1. Helical section of pipe

The pressure drop in the helical part amounts to:

$$
\Delta p=0.0175 \delta \lambda \frac{R}{d} \rho \frac{c^{2}}{2}
$$

For the given helical part: $\delta=3870^{\circ}, \mathrm{R}=0.0235 \mathrm{~m}$, $\mathrm{d}=0.004 \mathrm{~m}, \mathrm{c}=10.773 \mathrm{~m} / \mathrm{s}$ and the coefficient of hydraulic friction calculated from formula (2.6) amounts to $\lambda=0.144$. Substituting the data into formula (2.7) one gets $\Delta \mathrm{p}=29.26$ $105 \mathrm{~Pa}$.

Since for all the curved sections of the pipes $\mathrm{R}_{0} / \mathrm{D}_{0}>3$ and $50<\operatorname{Re}\left(2 \mathrm{R}_{0} / \mathrm{D}_{0}\right)^{-0.5}<600$ the following formula was used to calculate the pressure drop in the curved sections of the pipe [9]:

$$
\Delta p=0.0175 \frac{20}{R e^{0.65}}\left(\frac{D_{0}}{2 R_{0}}\right)^{0.175} \rho \frac{c^{2}}{2}
$$

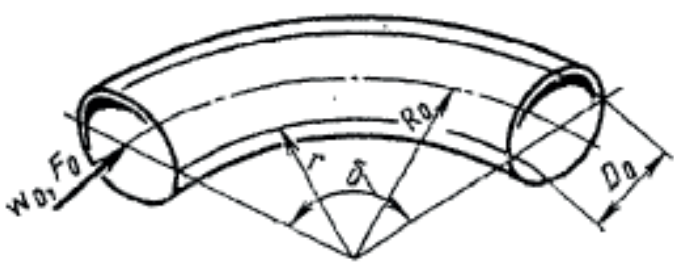

Fig. 2.2. Curved section of pipe [10]

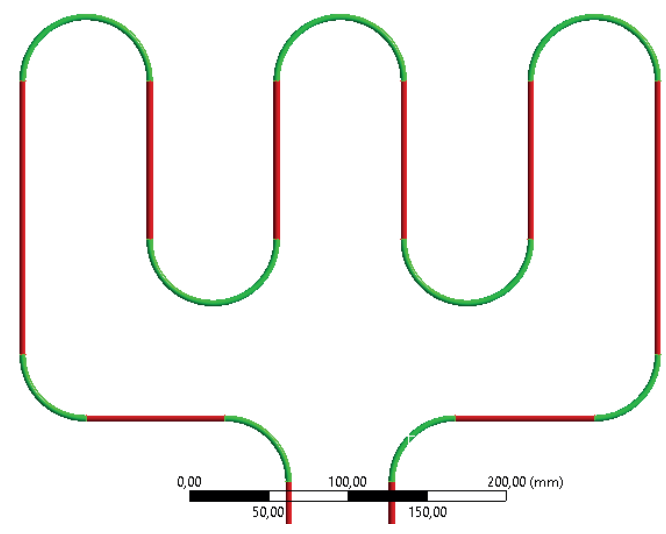

Fig. 2.3. Curved sections of pipe №3

Figure 2.3 shows the curved sections of pipe №3. 
The results of the calculations of pressure losses in the curved sections of the studied pipes are presented in table 2.3.

Table 2.3. Pressure losses in curved sections

\begin{tabular}{|l|c|c|c|}
\hline \multirow{2}{*}{ Calculated quantity } & \multicolumn{3}{|c|}{ Pipe number } \\
\cline { 2 - 4 } & №1 & №2 & №3 \\
\hline Pressure loss, $\mathrm{Pa}$ & $1.48 \cdot 10^{5}$ & $2.82 \cdot 10^{5}$ & $19.92 \cdot 10^{5}$ \\
\hline
\end{tabular}

Since the studied pipes were connected to the pressure gauges via a $66 \mathrm{~m}$ long adapter with an inside diameter of $22 \mathrm{~mm}$ the pressure losses in the straight section of the adapters were calculated from formula (2.2) while the pressure losses due to an abrupt extension and contraction were calculated from the formula [8]:

$$
\Delta p=\zeta_{M} \rho \frac{c^{2}}{2}
$$

The coefficient of local losses due to an abrupt extension is equal to [9]:

$\zeta_{M}=-8.44556-26.163\left(1-F_{0} / F_{1}\right)^{2}-5.38086\left(1-F_{0} / F_{1}\right)^{4}+$
$+\lg \operatorname{Re}\left[6.007+18.5372\left(1-F_{0} / F_{1}\right)^{2}+3.9978\left(1-F_{0} / F_{1}\right)^{4}\right]+$
$+(\lg \operatorname{Re})^{2}\left[-1.02318-3.0916\left(1-F_{0} / F_{1}\right)^{2}-0.680943\left(1-F_{0} / F_{1}\right)^{4}\right]$

where: $F_{0}$ - the cross-sectional area of the thinner pipe, $F_{1}-$ the cross-sectional area of the thicker pipe.

The coefficient of local losses due to an abrupt contraction is equal to [9]:

$$
\zeta_{M}=A \cdot \mathrm{B}\left(1-F_{0} / F_{1}\right)
$$

where:

$$
\begin{aligned}
& A=\sum_{i=0}^{7} a_{i}(\operatorname{lgRe})^{i} ; a_{0}=-25.12458 ; a_{1}=118.5076 ; \\
& a_{2}=-170.4147 ; a_{3}=118.1949 ; a_{4}=-44.42141 ; \\
& a_{5}=9.09524 ; a_{6}=-0.9244027 ; a_{7}=0.03408265 ;
\end{aligned}
$$

$$
\begin{aligned}
& B=\sum_{i=0}^{2}\left\{\left[\sum_{j=0}^{2} a_{i j}\left(\frac{F_{0}}{F_{1}}\right)^{j}\right](\operatorname{lgRe})^{i}\right\} ; \\
& a_{i j}=\left[\begin{array}{ccc}
1.07 & 1.22 & 2.9333 \\
0.05 & -0.51668 & 0.833 \\
0 & 0 & 0
\end{array}\right]
\end{aligned}
$$

The calculated pressure losses in the straight section of the adapters and the pressure losses due to an abrupt extension and an abrupt contraction, and the total losses in the adapters are presented in table 2.4 .

Tab. 2.4. Pressure losses in adapters

\begin{tabular}{|l|c|c|c|}
\hline \multirow{2}{*}{ Calculated quantity } & \multicolumn{3}{|c|}{ Pipe number } \\
\cline { 2 - 4 } & №1 & №2 & №3 \\
\hline $\begin{array}{l}\text { Pressure loss in straight section of } \\
\text { adapters, } \mathrm{Pa}\end{array}$ & 125 & 170 & 151 \\
\hline Pressure loss due to abrupt extension, $\mathrm{Pa}$ & $1.18 \cdot 10^{5}$ & $2.09 \cdot 10^{5}$ & $1.68 \cdot 10^{5}$ \\
\hline
\end{tabular}

\begin{tabular}{|l|c|c|c|}
\hline \multirow{2}{*}{ Calculated quantity } & \multicolumn{3}{|c|}{ Pipe number } \\
\cline { 2 - 4 } & №1 & №2 & №3 \\
\hline Pressure loss due to abrupt contraction, $\mathrm{Pa}$ & $0.36 \cdot 10^{5}$ & $0.6 \cdot 10^{5}$ & $0.49 \cdot 10^{5}$ \\
\hline Total losses in adapters, $\mathrm{Pa}$ & $1.54 \cdot 10^{5}$ & $2.15 \cdot 10^{5}$ & $2.17 \cdot 10^{5}$ \\
\hline
\end{tabular}

The total pressure losses in pipes and the difference in comparison with the pressure losses determined experimentally are presented in table 2.5.

Tab. 2.5. Analytical and experimental pressure losses in pipes

\begin{tabular}{|l|c|c|c|}
\hline \multirow{2}{*}{ Calculated quantity } & \multicolumn{3}{|c|}{ Pipe number } \\
\cline { 2 - 4 } & №1 & №2 & №3 \\
\hline $\begin{array}{l}\text { Analytical total pressure losses in pipe } \\
\Delta \mathrm{p} 2, \mathrm{~Pa}\end{array}$ & $33.15 \cdot 10^{5}$ & $27.89 \cdot 10^{5}$ & $34.1 \cdot 10^{5}$ \\
\hline Experimental pressure losses $\Delta \mathrm{p} 1, \mathrm{~Pa}$ & $40.98 \cdot 10^{5}$ & $31.93 \cdot 10^{5}$ & $42.17 \cdot 10^{5}$ \\
\hline
\end{tabular}

According to table 2.5, the theoretical pressure losses are lower than the experimental ones and the calculation error does not exceed $20 \%$. Considering that the calculations were done for the isothermal flow of the oil and that in the literature on the subject [9] one can find an empirical correction factor of $75 / 64=1.17$, the obtained results are satisfactory.

\section{CALCULATION OF LIQUID FLOW RESISTANCES BY MEANS OF NUMERICAL MODELLING}

\section{PROBLEM SETUP}

In this section the problem of the flow of the hydraulic oil in the studied pipes is solved by means of numerical modelling in ANSYS CFX. The solution was reached in several steps: the creation of the investigated object's geometry of, the generation of a finite volume element mesh, the setting of proper liquid parameters and boundary conditions, computations, an analysis of the pressure distribution in the pipes and of the pressure losses.

The parameters of the liquid needed for the calculations are: density $\rho=877 \mathrm{~kg} / \mathrm{m}^{3}$ and coefficient of dynamic viscosity $\mu=\rho \nu=0.04 \mathrm{~kg} \mathrm{~m}^{-1} \mathrm{~s}^{-1}$.

The pressure at the pipe's inlet and the mass rate of flow at the pipe's outlet, whose values are given in table 3.1, were set as the boundary conditions.

Tab. 3.1. Boundary conditions for numerical computations

\begin{tabular}{|l|c|c|c|}
\hline \multirow{2}{*}{ Parameter } & \multicolumn{3}{|c|}{ Pipe number } \\
\cline { 2 - 4 } & №1 & №2 & №3 \\
\hline Inlet pressure, $\mathrm{Pa}$ & $50 \cdot 10^{5}$ & $46 \cdot 10^{5}$ & $54 \cdot 10^{5}$ \\
\hline Outlet mass rate of flow, $\mathrm{kg} / \mathrm{s}$ & 0.119 & 0.161 & 0.143 \\
\hline
\end{tabular}

\section{COURSE OF NUMERICAL MODELLING}

First geometric models of the liquid for the studied pipes were created on the basis of the models of the pipes used in the experiments (fig. 3.1).

Subsequently a mesh of volume elements was generated. Prismatic elements with a characteristic size of $0.8 \mathrm{~mm}$ 
were used for this purpose. There were 5 boundary layers, the layer width amounted to $0.5 \mathrm{~mm}$ and the mesh growth rate to 1.2. A close-up of the volume element mesh is shown in fig. 3.2.

Then the boundary conditions were set according to table 3.1 (fig. 3.3). For all the models the inlet pressure, the outlet mass rate of flow and "hydraulically smooth" walls on all the surfaces, except for the pipe's inlet and outlet, were set.

The laminar flow of the liquid was assumed in the computations.

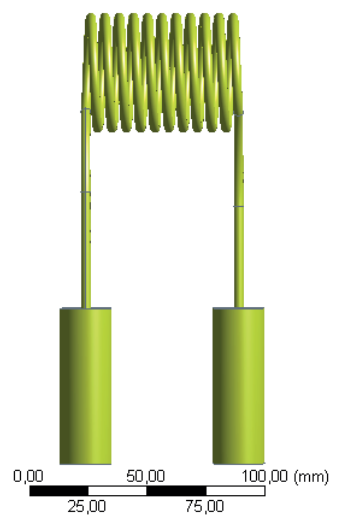

№1

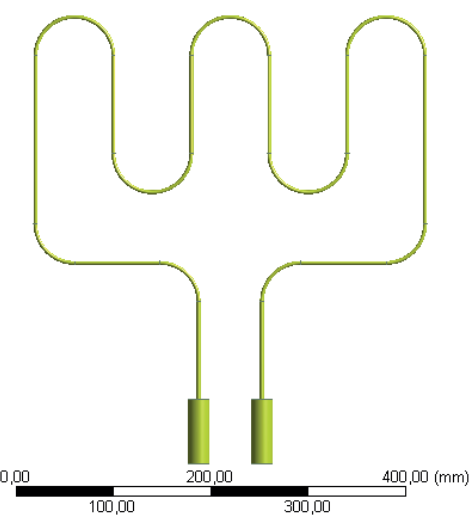

№3

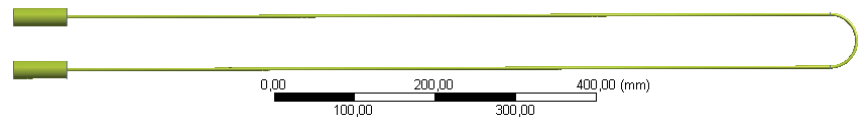

№2

Fig. 3.1. Geometric models of liquid for studied pipes

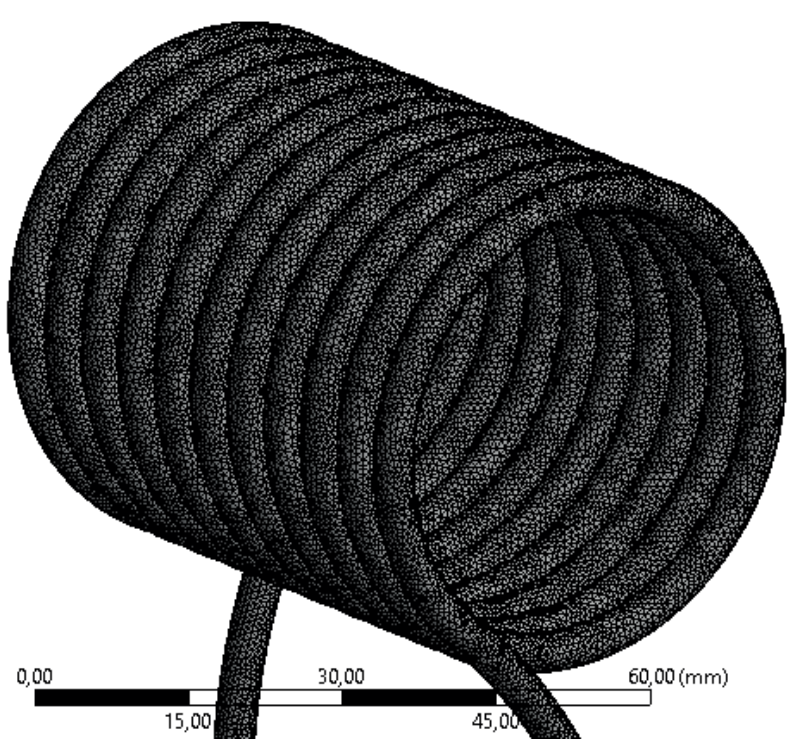

Fig. 3.2. Close-up of volume element mesh for pipe №1

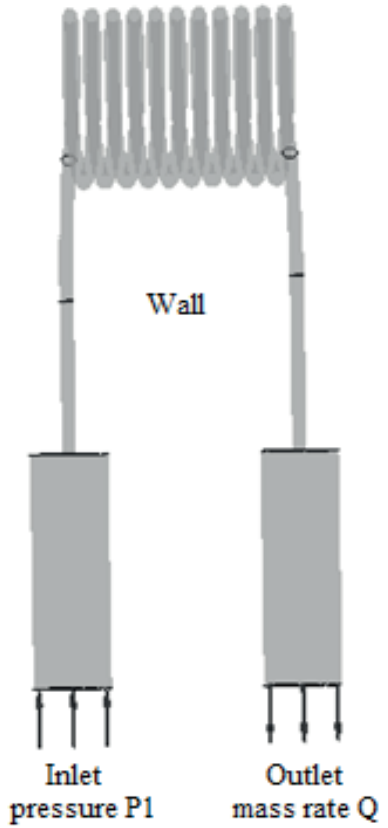

Fig. 3.3. Boundary conditions for computing oil flow in pip №1

\section{ANALYSIS OF COMPUTATION RESULTS}

Conducted CFD analysis helped to obtain the distribution of pressure drop during the flow of a liquid through investigated pipes Fig. 3.4.
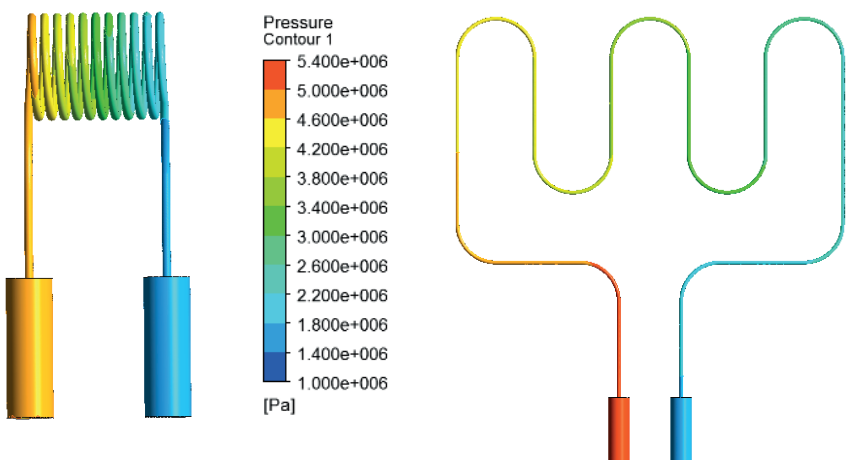

№1

№3

№2

Fig. 3.4. Distribution of pressure in pipes

Tab. 3.2. Total pressure losses in pipes, computed by means of numerical modelling

\begin{tabular}{|l|c|c|c|}
\hline \multirow{2}{*}{ Parameter } & \multicolumn{3}{c|}{ Pipe number } \\
\cline { 2 - 4 } & №1 & №2 & №3 \\
\hline Inlet pressure, $\mathrm{Pa}$ & $50 \cdot 10^{5}$ & $46 \cdot 10^{5}$ & $54 \cdot 10^{5}$ \\
\hline Outlet pressure, $\mathrm{Pa}$ & $17.06 \cdot 10^{5}$ & $15.39 \cdot 10^{5}$ & $17.72 \cdot 10^{5}$ \\
\hline Pressure losses in pipe, $\mathrm{Pa}$ & $32.94 \cdot 10^{5}$ & $30.61 \cdot 10^{5}$ & $36.28 \cdot 10^{5}$ \\
\hline
\end{tabular}


The total pressure losses in the pipes and the computation error in comparison with the experimentally determined pressure losses are presented in table 3.3.

Tab. 3.3. Pressure losses in pipes, computed by means of numerical modelling and determined experimentally

\begin{tabular}{|l|c|c|c|}
\hline \multirow{2}{*}{ Computed quantity } & \multicolumn{3}{c|}{ Pipe number } \\
\cline { 2 - 4 } & $№ 1$ & $№ 2$ & №3 \\
\hline $\begin{array}{l}\text { Total power losses in pipe computed by } \\
\text { means of numerical modelling } \\
\Delta \mathrm{p} 3, \mathrm{~Pa}\end{array}$ & $32.94 \cdot 10^{5}$ & $30.61 \cdot 10^{5}$ & $36.28 \cdot 10^{5}$ \\
\hline $\begin{array}{l}\text { Experimental power losses in pipe } \\
\Delta \mathrm{p} 1, \mathrm{~Pa}\end{array}$ & $40.98 \cdot 10^{5}$ & $31.93 \cdot 10^{5}$ & $42.17 \cdot 10^{5}$ \\
\hline $\begin{array}{l}\text { Error of computations by means } \\
\text { ofnumerical modelling } \\
{[(\Delta \mathrm{p} 1-\Delta \mathrm{p} 3) / \Delta \mathrm{p} 1] \cdot 100, \%}\end{array}$ & 19.6 & 4.1 & 14 \\
\hline
\end{tabular}

The results of the numerical modelling computations show that the pressure losses determined in this way are lower than the ones determined experimentally and the computation error does not exceed $20 \%$, while for pipe №2 with a long straight section the error amounts to $4.1 \%$, which can indicate good agreement between the experimental data and the numerical computations.

\section{CONCLUSION}

The experiment has shown that the highest pressure losses occur in the curved pipe. This can be due to the fact that most of the pressure drop in curved pipes is caused by the vortices arising on the interior wall as a result of the centrifugal force acting on the liquid.

The analytical calculations indicate that the calculation error in comparison with the experimental data amounts to $19 \%$. However, it should be noted that the calculations were carried out for the isothermal flow of the liquid, which is a simplifying assumption. In the literature on the subject $[8,9$, 11] one can find an empirical relation taking into account the non-isothermal character of the flow, in which the coefficient of linear losses is assumed to be equal to 75/Re instead of 64/ Re. Using the coefficient of linear losses which takes the nonisothermal character of the flow into account, the analytically calculated pressure losses will be $17 \%$ higher and so the error in comparison with the experimental pressure losses will be less than $5 \%$.

The numerical modelling showed very good agreement with the experimental data only in the case of pipe №2 with a long straight section. Whereas for the other two pipes the error amounts to respectively 19.6 and $14 \%$.

\section{REFERENCES}

1. P. Śliwiński, The influence of water and mineral oil on the leaks in satellite motor commutation unit clearances. Polish Maritime Research 3 (95) Vol. 24, pp. 58-67, (2017).
2. P. Sliwiński, The influence of water and mineral oil on volumetric losses in hydraulic motor. Polish Maritime Research S1 (93) Vol. 24, pp. 213-223, (2017).

3. F Yeaple, Fluid Power Design Handbook (Design News Magazine Cahners Publishing Company, Boston, Massachusetts, 1984).

4. N. H. C. Hwang, C. E. Hita, Fundamentals of Hydraulic Engineering Systems (Prentice-Hall, Inc, Englewood Cliffs, New Jersey,1987).

5. P. Śliwiński, "New satellite pumps", Key Engineering Materials Vol. 490, pp. 195-205, (2012).

6. http://olejefuchs.pl/fuchs-renolin-vg-46-20ltr.html Access date: 27.08.2017.

7. Z. Kudźma, Damping of Pressure Fluctuations and Noise in Transient and Steady States in Hydraulic Systems [in Polish] (Wrocław University of Science and Technology Publishing House, Wrocław, 2012).

8. Osiecki, Hydrostatic Drive for Machines [in Polish] (Warsaw, WNT, 2014).

9. I.E. Idelchik, Spravochnik po Gidravlicheskim Soprotivlenijam (Izdanie 3-e, Mashinostroenie, Moscow, 1992).

10. B.S.V.S.R. Krishna, "Prediction of Pressure Drop in Helical Coil with Single Phase Flow of Non-Newtonian Fluid," International Journal of Applied Research in Mechanical Engineering, Vol. 2, Iss. 1 (2012).

11. S. Stryczek, Hydrostatic Drive [in Polish] (WNT, Warsaw, 2005).

12. T. Takami, K. Sudou, "Flow through Curved Pipe with Elliptic Section,” Bulletin of JSME, Vol. 27. № 228. pp. 1176-1181 (1984). 


\section{CONTACT WITH THE AUTHORS}

Michał Stosiak

e-mail:michal.stosiak@pwr.edu.pl

Wrocław University of Science and Technology

Wybrzeże Stanisława Wyspiańskiego 27

50-370 Wrocław

Poland

Maciej Zawiślak

e-mail:maciej.zawislak@pwr.edu.pl

Wrocław University of Science and Technology

Wybrzeże Stanisława Wyspiańskiego 27

50-370 Wrocław

Poland

Bohdan Nishta

e-mail:bohdan.nishta@gmail.com

Sumy State University

Rymskogo-Korsakova 2

40-007 Sumy

UKRAINE 